\title{
Systematic Review of Patient-Reported Outcomes following Surgical Treatment of Lymphedema
}

\author{
Michelle Coriddi ${ }^{1, *}$, Joseph Dayan ${ }^{1}$, Nikhil Sobti ${ }^{2}$, David Nash ${ }^{3}$, Johanna Goldberg ${ }^{1}$ \\ Anne Klassen ${ }^{4}$, Andrea Pusic ${ }^{4}$ and Babak Mehrara ${ }^{1}$ \\ 1 Memorial Sloan Kettering Cancer Center, New York, NY 10065, USA; dayanj@mskcc.org (J.D.); \\ goldbej2@mskcc.org (J.G.); mehrarab@mskcc.org (B.M.) \\ 2 Boston University School of Medicine, Boston, MA 02118, USA; nsobti@bu.edu \\ 3 Montefiore Medical Center, New York, NY 10467, USA; dnash@montefiore.org \\ 4 Brigham and Women's Hospital, Boston, MA 02115, USA; aklass@mcmaster.ca (A.K.); \\ apusic@bwh.harvard.edu (A.P.) \\ * Correspondence: Coriddim@mskcc.org
}

Received: 26 January 2020; Accepted: 27 February 2020; Published: 29 February 2020

\begin{abstract}
Introduction: Analysis of quality of life (QOL) outcomes is an important aspect of lymphedema treatment since this disease can substantially impact QOL in affected individuals. There are a growing number of studies reporting patient-reported outcomes (PROMs) for patients with lymphedema. The purpose of this study was to conduct a systematic review of outcomes and utilization of PROMs following surgical treatment of lymphedema. Methods: A literature search of four databases was performed up to and including March, 2019. Studies included reported on QOL outcomes after physiologic procedures, defined as either lymphovenous bypass (LVB) or vascularized lymph node transplant (VLNT), to treat upper and/or lower extremity primary or secondary lymphedema. Results: In total, 850 studies were screened-of which, 32 studies were included in this review. Lymphovenous bypass was the surgical intervention in 16 studies, VLNT in 11 studies, and both in 5 studies. Of the 32 total studies, 16 used validated survey tools. The most commonly used PROM was the lymph quality of life measure for limb lymphedema (LYMQOL) (12 studies). In the remaining four studies, the upper limb lymphedema 27 scale (ULL27), the short form 36 questionnaire (SF-36), the lymphedema functioning, disability and health questionnaire (Lymph-ICF), and lymphedema life impact scale (LLIS) were each used once. QOL improvement following surgical treatment was noted in all studies. Conclusions: Physiologic surgical treatment of lymphedema results in improved QOL outcomes in most patients. The use of validated PROM tools is increasing but there is no current consensus on use. Future research to evaluate the psychometric properties of PROMs in lymphedema is needed to guide the development and use of lymphedema-specific tools.
\end{abstract}

Keywords: quality of life; lymphedema; lymphovenous bypass; lymph node transplant; patient-reported outcomes

\section{Introduction}

Lymphedema is a dreaded chronic disease affecting more than 5 million people in the United States [1]. Although primary lymphedema can arise from congenital or genetic mutations, the most common cause of lymphedema in Western countries is secondary to lymphatic injury in the course of surgical management of cancer (secondary lymphedema). The rates of lymphedema development following cancer treatment vary widely depending on the length of follow up and the methods used to define or measure lymphedema; however, some studies have reported lifetime rates as high as $50 \%$ following axillary lymph node dissection [2]. Further, while breast cancer is the most common 
cause of secondary lymphedema due to the high prevalence of this malignancy, lymphedema also occurs commonly in patients treated for other solid tumors including melanoma (16\%), gynecological cancers $(20 \%)$, genitourinary tumors $(10 \%)$, and head/neck malignancies $(4 \%)$ [3]. Risk factors can include radiation, large radiation field, conventional fractionation radiation, obesity, age, chemotherapy infusion to the affected limb, taxane-based chemotherapy, advanced stage disease, number of lymph nodes removed, and number of positive lymph nodes. [2,4-11] Secondary lymphedema can also result from traumatic injury or infections involving the lymphatic tree. Less frequently, secondary lymphedema can develop in patients due to extreme obesity.

Regardless of etiology, patients with lymphedema experience a variety of symptoms including swelling, pain, decreased range of motion, depression and anxiety [12-14]. These symptoms substantially impact quality of life (QOL) and are an important clinical aspect of this disease, resulting in negative changes in functional, social, and psychological domains. Importantly, some patients have profoundly decreased QOL even without significant changes in extremity circumference [15]. These findings suggest, therefore, that assessment of QOL is an important aspect of any study aiming to analyze outcomes following surgical treatment of lymphedema.

There are a number of patient-reported outcome measures (PROMs) available to study QOL in patients with lymphedema. Some of these instruments are lymphedema specific while others are more generic. Lymphedema-specific tools include the lymph quality of life measure for limb lymphedema (LYMQOL) [16], the upper limb lymphedema 27 scale (ULL27) [17], the lymphedema functioning, disability and health questionnaire (Lymph-ICF) [18], and the lymphedema life impact scale (LLIS) [19]. The short form 36 questionnaire (SF-36), is well known and widely used, but not specific to lymphedema [20]. Each tool is distinctive in its examination of QOL in patients with lymphedema and there is currently no consensus on which instrument to use for surgical patients.

While there is no cure for lymphedema, recent surgical treatments aiming to improve lymphatic drainage have gained popularity. These so called physiologic procedures include lymphovenous bypass (LVB), in which lymphatic channels are anastomosed to nearby veins to bypass zones of obstruction, and vascularized lymph node transplant (VLNT), in which lymph nodes are transplanted along with their blood supply to the lymphedematous limb. Interestingly, the majority of studies reporting on these procedures suggest that the best outcomes are obtained in patients with early stage disease and limited limb swelling [21]. This makes intuitive sense since it is widely accepted that early intervention for most diseases is associated with better outcomes. However, this fact also presents a clinical challenge in measuring outcomes since patients with early stage disease tend to have relatively small increases in limb volume excess. Thus, objective outcomes focusing on improvements in limb swelling may not fully capture the positive benefits of surgical intervention as reflected by changes in QOL. This problem is accentuated by the fact that there is no correlation between limb volume excess and impairments in QOL. As a result, these issues underline the importance of PROMs in the assessment of outcomes following lymphatic reconstruction. Nevertheless, to our knowledge, there has been no systematic review focusing on QOL after surgical treatment for lymphedema. Therefore, the purpose of this study was to perform a systematic review of subjective outcomes following LVB or VLNT and to analyze trends in PROM use in the literature.

\section{Methods}

A systematic review of contemporary peer-reviewed literature was performed to evaluate the QOL outcomes in the physiologic surgical treatment of lymphedema. On March 7, 2019, four databases were searched: Medline (PubMed), Embase.com, the Cochrane Library (Wiley), and Health and Psychosocial Instruments (Ovid). In all databases but Health and Psychosocial Instruments, the search had two main categories, combined using the AND operator: (1) lymphedema and (2) lymphovenous anastomosis or lymph node transplant. The search in Health and Psychosocial Instruments looked only for lymphedema-related instruments. In PubMed and Embase, we used the Cochrane Handbook filter 
for excluding animal-only studies [22]. We saved all references to the citation management software EndNote and removed duplicates following the Bramer Method [23].

Two reviewers independently reviewed 850 abstracts after removal of duplicates and 105 full texts. Clinical studies describing QOL outcomes after surgical treatment of extremity lymphedema with either LVB or VLNT, with a minimum sample size of four patients and written in English were included in our study. Non-referenced articles, case reports, review articles and non-human articles were excluded. A total of 32 studies matched inclusion criteria (Figure 1).

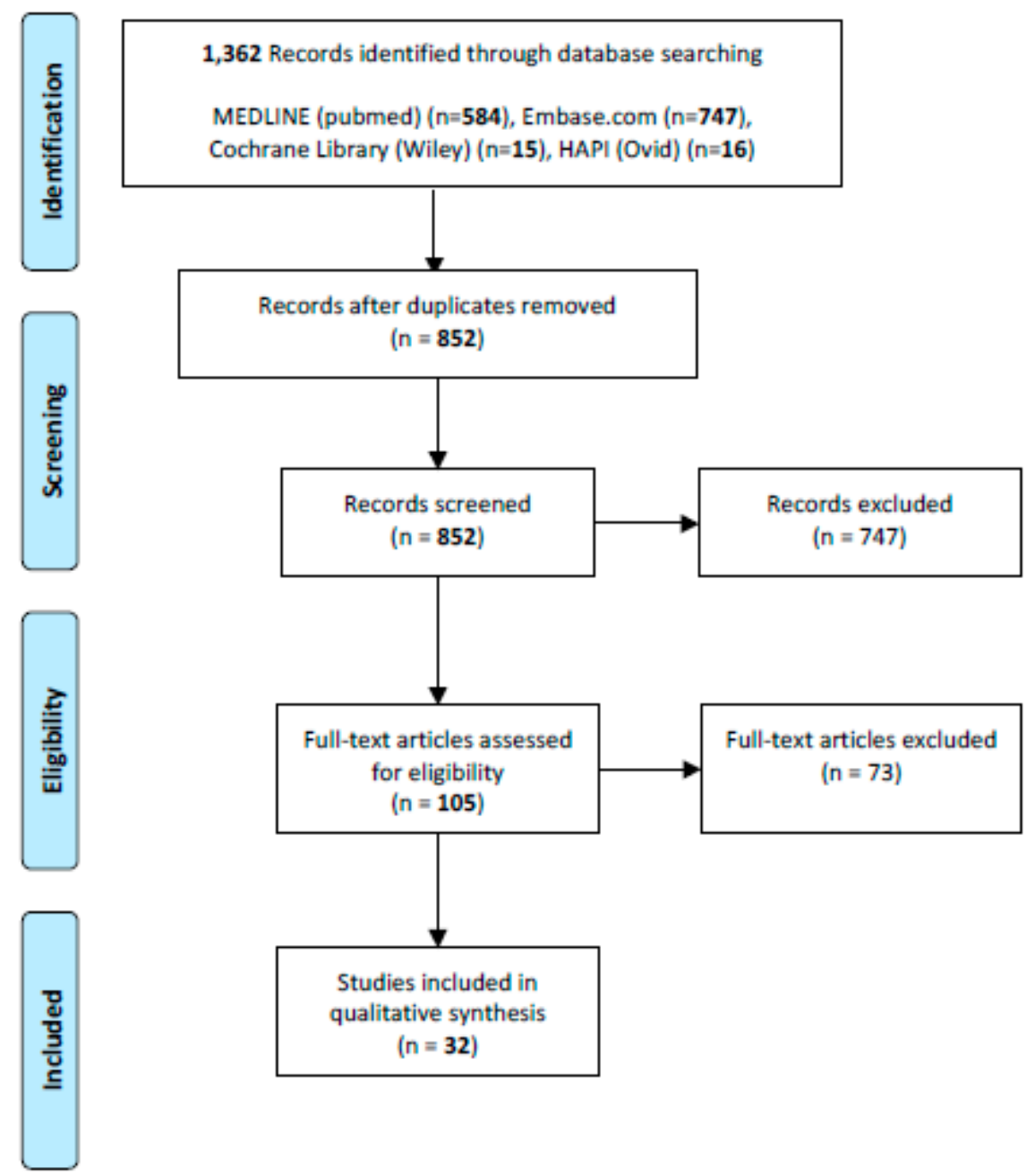

Figure 1. PRISMA (Preferred Reporting Items for Systematic Reviews and Meta-Analyses) chart.

Data extracted from each study included number of patients, etiology of lymphedema, stage of lymphedema, upper versus lower extremity, type of surgical procedure, other therapies used, donor site for VLNT, and follow up time/tool used for QOL assessment. Descriptive and summary statistics were used to evaluate the articles. Pearson correlation coefficient was used to assess the use of validated and ad-hoc survey tools over time.

\section{Results}

QOL was reported as an outcome measure after physiologic surgical treatment for lymphedema in 32 articles involving 954 patients. Weighted average follow-up time was 9.2 months. LVB was the primary surgical treatment in 18 studies, and VLNT in 14 studies. All studies showed an improvement in QOL (range 50-100\%). Individual patient data was reported in 18 studies, totaling 717 patients. Between $50 \%$ and $100 \%$ of patients showed improvement. One-half of the studies we reviewed $(n=16)$ 
used a QOL tool without evidence of a development or psychometric validation process (i.e., ad-hoc instrument). PROMs were used in the remainder of studies and included LYMQOL $(n=12,38 \%)$, the ULL27 $(n=1,3 \%)$, the Lymph-ICF $(n=1,3 \%)$, the LLIS $(n=1,3 \%)$ and the SF-36 $(n=1,3 \%$; (Table 1$)$. Over time, the proportion of studies utilizing validated tools increased $(\mathrm{r}=0.5)$, while the proportion of studies using an ad-hoc questionnaire decreased $(\mathrm{r}=-0.5)$ (Figure 2).

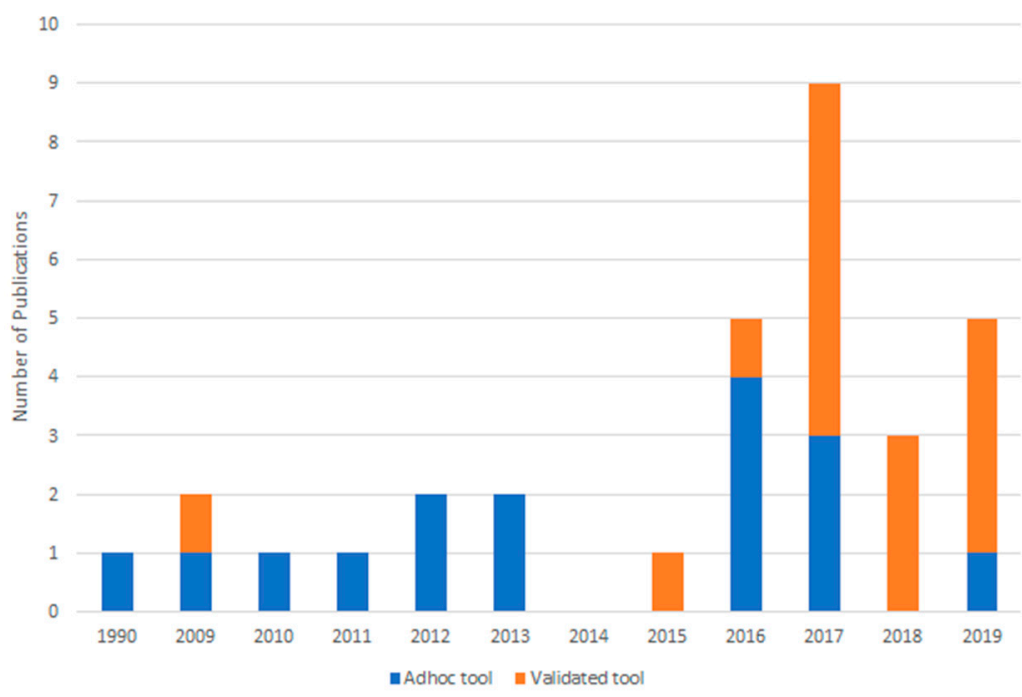

Figure 2. Publications with ad-hoc versus validated tools over time. 
Table 1. Validated quality of life tools.

\begin{tabular}{|c|c|c|c|c|c|c|}
\hline Validated Tool & $\begin{array}{l}\text { Lymphedema } \\
\text { Specific }\end{array}$ & Categories & $\begin{array}{l}\text { Number of } \\
\text { Questions }\end{array}$ & Lookback Period & $\begin{array}{l}\text { Upper/Lower } \\
\text { Extremity }\end{array}$ & Score Calculation \\
\hline LYMQOL & Yes & $\begin{array}{l}\text { Four subscales: pain, mood, } \\
\text { function and appearance, and } \\
\text { an additional question on } \\
\text { overall quality of life }\end{array}$ & 24 (upper) 25 (lower) & 1 week (mood only) & Both & $\begin{array}{l}\text { A 4-point Likert scale with } \\
\text { additional questions that are } \\
\text { free response. Each dimension } \\
\text { is scored, resulting in one } \\
\text { number for each section. The } \\
\text { overall quality of life score is } \\
\text { on a 1-10 scale. }\end{array}$ \\
\hline ULL27 & Yes & $\begin{array}{l}\text { Three subscales: physical, } \\
\text { psychological, and social }\end{array}$ & 27 & 4 weeks & Upper & $\begin{array}{l}\text { A 5-point Likert scale. Each } \\
\text { dimension is scored, resulting } \\
\text { in one number for each section. }\end{array}$ \\
\hline Lymph-ICF & Yes & $\begin{array}{l}\text { Five subscales: physical } \\
\text { function, mental function, } \\
\text { household activities, mobility } \\
\text { activities, and life and } \\
\text { social activities }\end{array}$ & 29 & 2 weeks & Both & $\begin{array}{l}\text { An 11-point Likert scale. Each } \\
\text { dimension is scored, resulting } \\
\text { in one number for each section. }\end{array}$ \\
\hline LLIS & Yes & $\begin{array}{l}\text { Three subscales: physical, } \\
\text { psychosocial, functional, and } \\
\text { an additional question on } \\
\text { infection occurrence }\end{array}$ & 18 & 1 week & Both & $\begin{array}{l}\text { A 5-point Likert scale. Each } \\
\text { dimension is scored, resulting } \\
\text { in one number for each section. }\end{array}$ \\
\hline SF-36 & No & $\begin{array}{l}\text { Eight subscales: physical } \\
\text { functioning, role limitations as } \\
\text { a result of physical problems, } \\
\text { bodily pain, general health } \\
\text { perception, vitality, social } \\
\text { functioning, role limitations } \\
\text { due to emotional problems, } \\
\text { and mental health }\end{array}$ & 36 & 4 weeks & Both & $\begin{array}{l}\text { The domains are combined to } \\
\text { create a physical component } \\
\text { score and a mental } \\
\text { component score. }\end{array}$ \\
\hline
\end{tabular}




\subsection{Patient-Reported Outcomes after LVB}

\subsubsection{Ad-Hoc Patient Questionnaires}

Twelve studies analyzing outcomes following LVB assessed QOL outcomes with ad-hoc questionnaires (Table 2). O'Brien et al. analyzed outcomes of 46 upper extremity and 6 lower extremity LVB procedures [24]. At an average follow up of 4.2 months, 38 of 52 (78\%) patients experienced subjective improvement including a decrease in size, better fitting clothes, softer skin and decreased frequency of cellulitis. A few patients, 3 of 52 (6\%) felt they were worse. Most patients, $83 \%$, were able to discontinue conservative measures post-operatively. Demirtas et al. performed LVB in the lower extremities of 42 patients [25]. At an average follow up of 11.8 months, 40 of 42 (95\%) patients were satisfied with the result and felt improved in terms of decreased size, decreased weight of the limb, softer, better texture of skin, easier fitting of clothes and decreased infections. Auba et al. performed LVB of either the upper or lower extremity in 10 patients [26]. Qualitative evaluation was done by recording subjective symptoms that patients reported during follow up. At 18 months follow up, 9 of $10(90 \%)$ patients reported noticeable improvements in their symptoms (skin induration, sensation of swelling, worsening in the summer, requirement of garments, difficulty wearing clothing, numbness, erythema and mobility). Ayestaray et al. studied 20 patients with lymphedema of the upper extremity [27]. LVB was performed and at 6 months post-operative, 19 of 20 (95\%) patients had improvements in their soft tissues. They also noted that 18 of 20 (90\%) patients moved to a better QOL, although there is no mention as to how QOL was measured. Chang et al. reported that 19 of 20 patients $(95 \%)$ that underwent LVB of the upper extremity had improvements in the symptoms of lymphedema (arm was lighter, softer and less painful) shortly following surgery [28]. However, at 12 months follow up, these findings were sustained in only 16 of 20 (80\%). In another study, Chang et al. reported on outcomes in 100 consecutive patients treated with LVB for either upper or lower extremity lymphedema [29]. Average follow up for upper extremity patients was 30.4 months and $96 \%$ of patients reported their arm felt lighter, softer, and less painful. Average follow up for lower extremity patients was 18.2 months and 57\% noted symptomatic improvement. Poumellec et al. reported that at 12.7 months after LVB for upper extremity lymphedema, substantial functional improvement was noted in 17 of $31(55 \%)$ patients, and moderate improvement in 9 (29\%) patients [30].

Three studies described creation of ad-hoc study specific tools. Chung et al. created their own questionnaire in a retrospective study of 18 patients undergoing LVB for either upper or lower extremity lymphedema [31]. The questionnaire had eight questions, scored from 0 to 5, with higher scores being better than lower scores. Three questions were related to volume, two questions were related to softness, and three questions were related to overall satisfaction. The questionnaire was administered at 6 months post-operatively. Scores were compared between patients with upper versus lower extremity lymphedema and between Campisi stage 2 and 3/4. Generally, patients with stage 2 upper extremity lymphedema had the highest average scores. Patients with stage 3/4 lower extremity lymphedema had the lowest average scores. Mihara et al. also created a study specific tool evaluating sensations of pain, strange feelings, and tension [32]. In 6 patients with secondary lower extremity lymphedema, all patients (100\%) noted improvements at 6 months post-operatively. In another study by Mihara et al, a study specific tool was used to inquire about limb softness, pain, and severity of lower extremity lymphedema [33]. At 18.3 months, 67 of 84 (80\%) patients had improvement and 4 felt worse. 
Table 2. Quality of life (QOL) in lymphovenous bypass (LVB) using ad-hoc tools.

\begin{tabular}{|c|c|c|c|c|c|c|c|c|c|c|}
\hline Study & $\begin{array}{c}\text { Year } \\
\text { Published }\end{array}$ & $\begin{array}{l}\text { Number of } \\
\text { Patients }\end{array}$ & Stage & $\begin{array}{l}\text { Lymphedema } \\
\text { Site }\end{array}$ & $\begin{array}{l}\text { Primary vs. } \\
\text { Secondary }\end{array}$ & Surgical Procedure & $\begin{array}{l}\text { Baseline QOL } \\
\text { Measure } \\
\text { Administered } \\
\text { Pre-Operatively? }\end{array}$ & $\begin{array}{l}\text { Average } \\
\text { Follow-Up } \\
\text { Time }\end{array}$ & $\begin{array}{c}\text { QOL } \\
\text { Measure }\end{array}$ & $\begin{array}{c}\text { Percent of } \\
\text { Patients with } \\
\text { Subjective } \\
\text { Improvement }\end{array}$ \\
\hline $\mathrm{O}^{\prime}$ Brien & 1990 & 52 & Not mentioned & UE (46), LE (6) & Secondary & LVB & Not mentioned & $4.2 \mathrm{mo}$ & Ad-hoc tool & $73 \%$ \\
\hline Demirtas et al. & 2009 & 42 & $\begin{array}{l}\text { Campisi stage II } \\
\text { (12), III (17), IV (13) }\end{array}$ & LE & $\begin{array}{c}\text { Secondary (34), } \\
\text { Primary (8) }\end{array}$ & LVB & Not mentioned & $11.8 \mathrm{mo}$ & Ad-hoc tool & $95 \%$ \\
\hline Chang & 2010 & 20 & $\begin{array}{l}\text { Capisi stage II (10), } \\
\text { III (10) }\end{array}$ & UE (20) & Secondary & LVB & Yes & $12 \mathrm{mo}$ & Ad-hoc tool & $80 \%$ \\
\hline Auba et al. & 2012 & 10 & $\begin{array}{c}\text { Campisi stage II (2), } \\
\text { III (8) }\end{array}$ & LE (4), UE (6) & $\begin{array}{c}\text { Secondary (9), } \\
\text { Primary (1) }\end{array}$ & LVB & No & $18 \mathrm{mo}$ & Ad-hoc tool & $90 \%$ \\
\hline Mihara et al. & 2012 & 6 & ISL $0(3), 1$ (3) & LE & Secondary & LVB & Yes & $6 \mathrm{mo}$ & Ad-hoc tool & $100 \%$ \\
\hline Ayestaray et al. & 2013 & 20 & $\begin{array}{l}\text { Campisi stage II (9), } \\
\text { III (7), IV (3), V (1) }\end{array}$ & UE & Not mentioned & LVB & Yes & $6 \mathrm{mo}$ & Ad-hoc tool & $95 \%$ \\
\hline Chang et al. & 2013 & 100 & $\begin{array}{l}\text { ICG classification } \\
\text { stage } 1 \text { or } 2(16), 3 \text { or } \\
4 \text { (14). Not all } \\
\text { patients classified }\end{array}$ & UE (89), LE (11) & Secondary & LVB & Not mentioned & $\begin{array}{c}30.4 \mathrm{mo} \\
\text { (UE), } 18.2 \\
\text { mo (LE) }\end{array}$ & Ad-hoc tool & $\begin{array}{l}96 \% \text { (UE), } \\
57 \% \text { (LE) }\end{array}$ \\
\hline Mihara et al. & 2016 & 84 & $\begin{array}{l}\text { ISL } 1(30), 2 \mathrm{a}(39) \\
2 \mathrm{~b}(36), 3(23)\end{array}$ & LE & $\begin{array}{l}\text { Primary (15), } \\
\text { Secondary (69) }\end{array}$ & LVB & Yes & $18.3 \mathrm{mo}$ & Ad-hoc tool & $80 \%$ \\
\hline Chen et al. & 2016 & 21 & $\begin{array}{c}\text { Campisi I and II (9), } \\
\text { III (4), IV (8) }\end{array}$ & UE (13), LE (8) & $\begin{array}{c}\text { Primary (4), } \\
\text { Secondary (17) }\end{array}$ & LVB (18) or VLNT (3) & Yes & $12 \mathrm{mo}$ & Ad-hoc tool & $100 \%$ \\
\hline Masia et al. & 2016 & 200 & Not mentioned & UE (200) & Secondary (200) & $\begin{array}{l}\text { LVB (81), VLNT (7), } \\
\text { DIEP/SIEA with groin } \\
\text { lymph nodes (16), } \\
\text { LVB+VLNT (44), } \\
\text { liposuction (52) }\end{array}$ & Yes & $12 \mathrm{mo}$ & Ad-hoc tool & $96 \%$ \\
\hline Poumellec et al. & 2017 & 31 & $\begin{array}{c}\text { Campisi stage } 2(18) \\
3(10), 4(3)\end{array}$ & UE & Secondary & LVB & Yes & $12.7 \mathrm{mo}$ & Ad-hoc tool & $84 \%$ \\
\hline Chung et al. & 2019 & 18 & $\begin{array}{c}\text { Campisi stage II (7), } \\
\text { III or IV (11) }\end{array}$ & UE (8), LE (10) & Secondary & LVB & No & $6 \mathrm{mo}$ & Ad-hoc tool & $\begin{array}{l}\text { Individual } \\
\text { patient data not } \\
\text { reported }\end{array}$ \\
\hline
\end{tabular}

ISL, international society of lymphology; UE, upper extremity; LE, lower extremity; LVB, lymphovenous bypass; VLNT, vascularized lymph node transplant; DIEP, deep inferior epigastric perforator flap; SIEA, superficial inferior epigastric perforator flap; mo, months. 
Two studies reported outcomes of LVB, with or without VLNT, using ad-hoc study specific tools. Chen et al. used a study specific tool evaluating severity of lymphedema symptoms and degree of disability and reported that these symptoms are reversed by LVB in 19 patients and VLNT from the groin (1 patient) or supraclavicular region (2 patients) at 12 months follow up [34]. Significant improvement in scores was noted from pre-operative to post-operative $(p<0.01)$. Masia et al. used a study specific tool evaluating episodes of lymphangitis, pain, swelling, heaviness, loss of sensitivity, loss of mobility, anxiety/depression, impact on daily activities, and the use of conservative therapies [35]. Two hundred patients with upper extremity lymphedema were included in the study having the following procedures: LVB (81 patients), VLNT from the groin (7 patients), DIEP/SIEA with groin lymph nodes (16 patients), LVB + VLNT (44 patients), liposuction (52 patients). Of all patients, 192 (96\%) reported subjective improvement, 8 patients reported no change.

\subsubsection{LYMQOL}

Four papers reported on LVB outcomes using the LYMQOL (Table 3). Winters et al, in two separate studies-one with 29 patients and 12 month follow up and another with 12 patients and 6 month follow up-compared pre-operative to post-operative LYMQOL surveys in patients with upper extremity lymphedema [36,37]. In both studies, all subscales and the overall quality of life improved significantly $(p<0.01)$. Gentileschi et al. reported a significant increase in the average overall score using the LYMQOL at 6 months after LVB for treatment of upper extremity lymphedema in 16 patients $(p<0.001)$ [38]. Salgarello et al. used the LYMQOL to evaluate outcomes of LVB for treatments of either upper extremity $(n=44)$ or lower extremity $(n=26)$ lymphedema at an average of 8.5 months [39]. Significant improvements were noted in the overall score as well as all subscales $(p<0.01)$. 
Table 3. QOL in LVB using validated tools.

\begin{tabular}{|c|c|c|c|c|c|c|c|c|c|c|}
\hline Study & $\begin{array}{c}\text { Year } \\
\text { Published }\end{array}$ & $\begin{array}{l}\text { Number of } \\
\text { Patients }\end{array}$ & Stage & $\begin{array}{l}\text { Lymphedema } \\
\text { Site }\end{array}$ & $\begin{array}{l}\text { Primary vs. } \\
\text { Secondary }\end{array}$ & $\begin{array}{l}\text { Surgical } \\
\text { Procedure }\end{array}$ & $\begin{array}{l}\text { Baseline QOL } \\
\text { Measure } \\
\text { Administered } \\
\text { Pre-Operatively? }\end{array}$ & $\begin{array}{c}\text { Average Follow-Up } \\
\text { Time Regarding } \\
\text { Subjective } \\
\text { Assessment }\end{array}$ & $\begin{array}{c}\text { QoL } \\
\text { Measure }\end{array}$ & $\begin{array}{l}\text { Percent of Patients } \\
\text { with Subjective } \\
\text { Improvement }\end{array}$ \\
\hline Damstra et al. & 2009 & 10 & $\begin{array}{c}\text { Campisi stage } \\
\text { III (10) }\end{array}$ & UE & Secondary & LVB & Yes & $6 \mathrm{mo}$ & SF-36 & $50 \%$ \\
\hline Cornelissen et al. & 2017 & 20 & ISL 1 (1), 2a (19) & UE & Secondary & LVB & Yes & $12 \mathrm{mo}$ & Lymph-ICF & $\begin{array}{l}\text { Individual patient } \\
\text { data not reported }\end{array}$ \\
\hline Gentileschi et al. & 2017 & 16 & ISL 2a (7), 2b (9) & UE & Secondary & LVB & Yes & $6 \mathrm{mo}$ & LYMQOL & $\begin{array}{l}\text { Individual patient } \\
\text { data not reported }\end{array}$ \\
\hline Winters et al. & 2017 & 29 & $\begin{array}{c}\text { Campisi stages } \\
1 \mathrm{~b}-2 \mathrm{a}\end{array}$ & UE & Secondary & LVB & Yes & $12 \mathrm{mo}$ & LYMQOL & $\begin{array}{l}\text { Individual patient } \\
\text { data not reported }\end{array}$ \\
\hline Salgarello et al. & 2018 & 74 & Not mentioned & UE (44), LE (26) & $\begin{array}{c}\text { Primary (5), } \\
\text { Secondary (55) }\end{array}$ & LVB & Yes & $8.5 \mathrm{mo}$ & LYMQOL & $\begin{array}{l}\text { Individual patient } \\
\text { data not reported }\end{array}$ \\
\hline Winters et al. & 2019 & 12 & $\begin{array}{c}\text { Campisi stages } \\
1-2 a\end{array}$ & UE & Secondary & LVB & Yes & $6 \mathrm{mo}$ & LYMQOL & $\begin{array}{l}\text { Individual patient } \\
\text { data not reported }\end{array}$ \\
\hline
\end{tabular}

ISL, international society of lymphology; UE, upper extremity; LE, lower extremity; LVB, lymphovenous bypass; mo, months; SF-36, short form 36 questionnaire; Lymph-ICF, lymphedema functioning, disability and health questionnaire; LYMQOL, lymph quality of life measure for limb lymphedema.

Table 4. QOL in VLNT using ad-hoc tools.

\begin{tabular}{|c|c|c|c|c|c|c|c|c|c|c|c|}
\hline Study & $\begin{array}{c}\text { Year } \\
\text { Published }\end{array}$ & $\begin{array}{l}\text { Number of } \\
\text { Patients }\end{array}$ & Stage & $\begin{array}{l}\text { Lymphedema } \\
\text { Site }\end{array}$ & $\begin{array}{l}\text { Primary vs. } \\
\text { Secondary }\end{array}$ & $\begin{array}{l}\text { Surgical } \\
\text { Procedure }\end{array}$ & $\begin{array}{l}\text { Donor Site } \\
\text { (Lymph Node } \\
\text { Transplant) }\end{array}$ & $\begin{array}{l}\text { Baseline QOL } \\
\text { Measure } \\
\text { Administered } \\
\text { Pre-Operatively? }\end{array}$ & $\begin{array}{c}\text { Average } \\
\text { Follow-Up Time } \\
\text { Regarding } \\
\text { Subjective } \\
\text { Assessment }\end{array}$ & $\begin{array}{c}\mathrm{QOL} \\
\text { Measure }\end{array}$ & $\begin{array}{c}\text { Percent of } \\
\text { Patients with } \\
\text { Subjective } \\
\text { Improvement }\end{array}$ \\
\hline Dionyssiou et al. & 2016 & 18 & ISL stage II (18) & UE & Secondary & VLNT & Groin & Yes & $12 \mathrm{mo}$ & $\begin{array}{c}\text { Ad-hoc } \\
\text { tool }\end{array}$ & $100 \%$ \\
\hline Coriddi et al. & 2017 & 15 & Not mentioned & UE (8), LE (7) & Secondary & VLNT & $\begin{array}{c}\text { Jejunal } \\
\text { Mesentery }\end{array}$ & Not mentioned & $9.1 \mathrm{mo}$ & $\begin{array}{c}\text { Ad-hoc } \\
\text { tool }\end{array}$ & $86 \%$ \\
\hline Nguyen et al. & 2017 & 42 & $\begin{array}{l}\text { Modified ICG } \\
\text { stage } 3(9), 4 \\
(18), 5(15)\end{array}$ & $\begin{array}{c}\text { UE (19), LE } \\
\text { (24) }\end{array}$ & $\begin{array}{c}\text { Secondary (37), } \\
\text { Primary (2), not } \\
\text { mentioned (3) }\end{array}$ & $\begin{array}{l}\text { VLNT ( } 55 \% \\
\text { also having } \\
\text { LVA) }\end{array}$ & Omentum & Not mentioned & $14 \mathrm{mo}$ & $\begin{array}{c}\text { Ad-hoc } \\
\text { tool }\end{array}$ & $83 \%$ \\
\hline
\end{tabular}

ISL, international society of lymphology; UE, upper extremity; LE, lower extremity; LVB, lymphovenous bypass; VLNT, vascularized lymph node transplant; mo, months. 


\subsubsection{Lymph-ICF}

Cornelissen et al. performed LVB on 20 patients with upper extremity lymphedema and the Lymph-ICF was used to evaluate outcomes at 12 months [40]. Significant improvements in all subscales and total score was seen $(p<0.05)$. (Table 3$)$.

\subsubsection{SF-36}

Damstra et al. performed LVB on 10 patients with upper extremity lymphedema [41]. SF-36 was completed pre-operatively and at 6 months post-operatively. At a follow up of 6 months, 5 of 10 patients (50\%) felt less disabled on the SF-36 questionnaire. (Table 3).

\subsection{Patient-Reported Outcomes after VLNT}

\subsubsection{Ad-Hoc Patient Questionnaires}

Four studies analyzing VLNT assessed QOL outcomes with no specific validated tool (Table 4). Gharb et al. evaluated 21 patients with upper extremity lymphedema who underwent VLNT using groin lymph nodes [42]. Ten patients also had liposuction. At an average of 43.1 months, average scores on a visual analog scale improved, although not significantly. Nguyen et al. report their series of 42 patients who had vascularized omentum flaps for treatment of either upper or lower extremity lymphedema, with 55\% of patients also having LVB [43]. Average follow up was 14 months and they report subjective improvements in swelling, fatigue, heaviness, tightness, stiffness, sleep loss, aching, and skin quality in 35 of 42 patients (83\%). There is no mention as to how data regarding symptoms was obtained and when.

Coriddi et al. analyzed results of the vascularized jejunal mesenteric lymph node transplant in 15 patients with either upper or lower extremity lymphedema [44]. One patient suffered a flap loss. At a mean follow up of 9.1 months, 12 of 14 patients had subjective improvement (85.7\%). Further details are not mentioned. Dionyssiou et al. published their results of a randomized control trial comparing VLNT from the groin to the upper extremity compared to conservative treatment over a follow up period of 12 months [45]. A visual analogue scaling system (1-10) was used to assess pain, heaviness and functional disturbances. All 18 patients (100\%) who received VLNT reported significant improvement at 12 months from pre-operative measurements in the pain, heaviness and function scales $(p<0.001)$. Additionally, when comparing groups, the scores for pain, heaviness and function were significantly better at 12 months in the VLNT group compared to the conservative management group $(p<0.001)$.

\subsubsection{LYMQOL}

Eight papers reporting on VLNT utilized the LYMQOL in outcome analysis (Table 5). Ciudad et al. report their results of transplant of the right gastroepiploic lymph node flap to either the groin (5 patients) or axilla (5 patients) [46]. When comparing average pre-operative scores with average one year post-operative scores, significant improvements in all subscales as well as the overall score were noted $(\mathrm{p}<0.01)$. Patel et al. examined 25 patients, 15 upper extremity and 10 lower extremity, with either primary or secondary lymphedema [47]. VLNT was done using either a groin or submental lymph node flap. Average LYMQOL scores were recorded pre-operatively and at 1, 3, 6, 9 and 12 months post-operation. In both the upper and lower extremity patients, all subscales were improved and reached statistical significance by 9 months post-operation (range $\mathrm{p}<0.01$ to $\mathrm{p}<0.05$ ). Asuncion et al. use LYMQOL pre-operatively and at 12 months post-operatively to evaluate outcomes of 15 patients who underwent submental VLNT to either upper or lower extremity [48]. At 12 months, there was a significant improvement in the average score for all subscales and overall QOL (range $p<0.02-p$ $<0.04$ ). Ciudad et al. reported their results following double gastroepiploic VLNT combined with soft tissue de-bulking [49]. At 12 months post-operation, significant improvements in the average scores in all subscales as well as the overall score were noted for both the upper and lower extremity 
groups $(p<0.01)$. Visconti et al. reported the technique and outcomes of compartmental dual lymph node transplant from the right supraclavicular area to the lower extremity in 10 patients with lymphedema [50]. LYMQOL surveys were completed pre-operatively and at 6 and 12 months post-operatively. All patients reported improvement in QOL. Average scores for all subscales and overall score improved from the pre-operative survey to the 6 month post-operative survey, and again from the 6 month survey to 12 month survey. Maruccia performed VLNT using groin or gastroepiploic lymph nodes to the upper extremity in 39 patients [51]. In 18 of the 39, scar release and fat grafting were performed as well. At 12 months follow up, LYMQOL average scores for both groups were significantly improved $(p<0.001)$.

Gratzon et al. used the LYMQOL and also two paper specific scales (pain and heaviness) to evaluate outcomes in 50 patients [52]. The pain scale and heaviness scales were both based on a standard 1-10 ratings. Evaluation was done pre-operatively and at 1, 3, 6, 9 and 12 months post-operatively. Twenty-four patients completed follow up at one year and had either a groin, lateral thoracic or supraclavicular VLNT to the upper extremity for secondary lymphedema. In terms of LYMQOL outcomes, all subscales and the overall score reached significant improvement by 3 months post-operation $(p<0.01)$. Using the paper specific pain and heaviness scales, pain reached significant $(p<0.01)$ improvement at 1 month post-operation and heaviness reached significant $(p<0.01)$ improvement at 1 month post-operation.

Cheng et al. evaluated 19 patients using the LYMQOL-15 who underwent submental VLNT and 4 who underwent LVB [53]. At 12 months follow up, average scores for all domains and the overall QOL score improved significantly in the VLNT groups $(p<0.05)$. The LVB group showed improvement in the overall score, and the function, appearance, symptoms and mood domains $(p=0.07,0.1,0.1$, $0.07,0.07$ respectively). 
Table 5. QOL in VLNT using validated tools.

\begin{tabular}{|c|c|c|c|c|c|c|c|c|c|c|c|}
\hline Study & $\begin{array}{c}\text { Year } \\
\text { Published }\end{array}$ & $\begin{array}{l}\text { Number of } \\
\text { Patients }\end{array}$ & Stage & Lymphedema Site & $\begin{array}{l}\text { Primary vs. } \\
\text { Secondary }\end{array}$ & $\begin{array}{c}\text { Surgical } \\
\text { Procedure }\end{array}$ & $\begin{array}{l}\text { Donor Site } \\
\text { (Lymph Node } \\
\text { Transplant) }\end{array}$ & $\begin{array}{c}\text { Baseline QOL } \\
\text { Measure } \\
\text { Administered } \\
\text { Pre-Operatively? }\end{array}$ & $\begin{array}{c}\text { Average } \\
\text { Follow-Up Time } \\
\text { Regarding } \\
\text { Subjective } \\
\text { Assessment }\end{array}$ & QoL Measure & $\begin{array}{l}\text { Percent of } \\
\text { Patients with } \\
\text { Subjective } \\
\text { Improvement }\end{array}$ \\
\hline Patel et al. & 2015 & 25 & $\begin{array}{l}\text { Scale specific to this } \\
\text { paper, I (1), II (6), III } \\
\text { (13), IV (5) }\end{array}$ & UE (15), LE (10) & $\begin{array}{c}\text { Secondary (23), } \\
\text { Primary (2) }\end{array}$ & VLNT & $\begin{array}{l}\text { Groin or } \\
\text { submental }\end{array}$ & Yes & $12 \mathrm{mo}$ & LYMQOL & $\begin{array}{l}\text { Individual patient } \\
\text { data not reported }\end{array}$ \\
\hline $\begin{array}{c}\text { De } \\
\text { Brucker et al. }\end{array}$ & 2016 & 25 & $\begin{array}{c}\text { Stage } 1 \text { and } 2 \\
\text { (classification system } \\
\text { and number of } \\
\text { patients per stage not } \\
\text { mentioned) }\end{array}$ & UE & Secondary & VLNT & Groin & No & $29 \mathrm{mo}$ & ULL27 & $84 \%$ \\
\hline Ciudad et al. & 2017 & 10 & $\begin{array}{l}\text { ISL stage II (2), ISL } \\
\text { stage III (8) }\end{array}$ & UE (5), LE (5) & Secondary & VLNT & $\begin{array}{l}\text { Right } \\
\text { gastroepiploic } \\
\text { lymph node } \\
\text { flap }\end{array}$ & Yes & $14.7 \mathrm{mo}$ & LYMQOL & $\begin{array}{l}\text { Individual patient } \\
\text { data not reported }\end{array}$ \\
\hline Gratzon et al. & 2017 & 24 & Not mentioned & UE & Secondary & VLNT & $\begin{array}{c}\text { Groin, lateral } \\
\text { thoracic, } \\
\text { supraclavicular }\end{array}$ & Yes & $12 \mathrm{mo}$ & $\begin{array}{l}\text { LYMQOL and study } \\
\text { specific pain scale } \\
\text { and heaviness scale } \\
\text { with standard } \\
1-10 \text { rating }\end{array}$ & $\begin{array}{l}\text { Individual patient } \\
\text { data not reported }\end{array}$ \\
\hline Inbal et al. & 2017 & 11 & ISL stage $1(4), 2$ (7) & $\mathrm{UE}(8), \mathrm{LE}(3)$ & Secondary & $\begin{array}{l}\text { VLNT (64\% also } \\
\text { having LVB) }\end{array}$ & $\begin{array}{l}\text { Thoracic on } \\
\text { muscle sparing } \\
\text { latissimus } \\
\text { dorsi flap }\end{array}$ & Yes & $6.7 \mathrm{mo}$ & LLIS & $91 \%$ \\
\hline Cheng et al. & 2018 & 19 & Not mentioned & $\operatorname{LE}(19)$ & Primary (19) & VLNT (15), LVB (4) & Submental & Yes & $12 \mathrm{mo}$ & LYMQOL & $\begin{array}{l}\text { Individual patient } \\
\text { data not reported }\end{array}$ \\
\hline Asuncionet al. & 2018 & 15 & Not mentioned & $\begin{array}{l}\text { LE (10), UE (4), } \\
\text { both LE/UE (1) }\end{array}$ & Not mentioned & VLNT & Submental & Yes & $12 \mathrm{mo}$ & LYMQOL & $\begin{array}{c}\text { Individual } \\
\text { pre-operative } \\
\text { patient data not } \\
\text { reported }\end{array}$ \\
\hline Ciudad et al. & 2019 & 16 & ISL stage III (16) & UE (6), LE (10) & $\begin{array}{c}\text { Secondary (15), } \\
\text { Primary (1) }\end{array}$ & $\begin{array}{l}\text { VLNT (with } \\
\text { debulking) }\end{array}$ & Gastroepiploic & Yes & $12 \mathrm{mo}$ & LYMQOL & $\begin{array}{l}\text { Individual patient } \\
\text { data not reported }\end{array}$ \\
\hline Maruccia et al. & 2019 & 39 & Not mentioned & UE & Secondary & $\begin{array}{l}\text { VLNT (18 also } \\
\text { with axillary scar } \\
\text { release and fat } \\
\text { grafting) }\end{array}$ & $\begin{array}{c}\text { Groin (20), } \\
\text { Gastroepiploic } \\
\text { (19) }\end{array}$ & Yes & $12 \mathrm{mo}$ & LYMQOL & $\begin{array}{l}\text { Individual patient } \\
\text { data not reported }\end{array}$ \\
\hline Visconti et al. & 2019 & 10 & ISL $2 b(10)$ & LE & Secondary & VLNT & Supraclavicular & Yes & $12 \mathrm{mo}$ & LYMQOL & $100 \%$ \\
\hline
\end{tabular}

ISL, international society of lymphology; UE, upper extremity; LE, lower extremity; LVB, lymphovenous bypass; VLNT, vascularized lymph node transplant; mo, months. 


\subsubsection{ULL27}

One study utilized the ULL27 in outcome analysis (Table 5). De Brucker et al. performed VLNT to the axilla of the affected arm using the groin as the flap donor site [54]. At an average follow up time of 29 months (range 8-64 months), there was a statistically significant improvement in the mean overall score of the ULL27 $(p<0.001)$. Average post-operative scores for each of the ULL27 domains (physical, psychological, social) also improved. Looking at individual data, 21 of 25 patients had improved scores, 3 patients had no change, and 1 patient was worse.

\subsubsection{LLIS}

The LLIS was used to assess outcomes in 14 patients who underwent VLNT using a muscle-sparing latissimus dorsi flap [55]. Inbal et al. report at a mean follow up of 6.7 months (range 3-12 months), 10 patients $(91 \%)$ reported symptomatic improvement including softer, lighter and less painful extremities than prior to surgery. Average LLIS scores improved over time. However, of 14 patients, only 9 patients presented for evaluation at 3 months follow up and only 5 patients at 12 months. (Table 5).

\section{Discussion}

QOL improvement was reported in all papers evaluated in this systematic review examining outcomes after LVB and/or VLNT in patients with either upper or lower extremity secondary or primary lymphedema. QOL is an important outcome measure in lymphedema surgery. Previous studies have shown that although volume changes may not be evident, patients with lymphedema can have significant QOL impairments. Additionally, the severity of volume change does not necessarily correlate with subjective outcomes, as patients with relatively minor volume changes can experience very significant psychosocial and/or physical challenges $[15,56]$. Hormes et al. found in his study of 295 women, arm swelling and lymphedema severity were less correlated with QOL than total number of arm symptoms and specific individual symptoms [15]. A study of breast cancer patients treated with neoadjuvant chemotherapy and axillary lymph node dissections showed slight agreement, with the kappa coefficient ranging from 0.05 to 0.09 , when examining lymphedema symptoms of arm swelling and heaviness compared to volume or circumference measurements [57]. At our institution, we have seen some patients with minimal or low excess volumes measurements report a high degree of impairment in QOL [56]. Despite these facts, the vast majority of studies reporting outcomes following surgical treatment of lymphedema have focused primarily on objective changes in limb volume or fluid content while a relative minority have also reported on PROMs. To our knowledge, this is the first systematic review of QOL changes following surgical physiologic lymphatic reconstruction.

Our systematic review found that QOL improvements can occur relatively early following surgery. The average weighted follow up for all studies was 9 months. Two papers that evaluated QOL using the LYMQOL found significant improvements in as little as 1 month post-operatively. Gratzon et al. reporting outcomes following VLNT to the upper extremity, found that the subscale of symptoms on the LYMQOL is significantly improved as early as 1 month after surgery. Additionally, at one month post-operatively, pain and heaviness improved significantly when measured on their paper specific scale [52]. Patel et al. reported significant improvement on the LYMQOL function subscale 1 month following VLNT in 15 patients with upper extremity lymphedema [47]. Studies with longer term follow up are needed to ensure these findings persist and are not simply related to post-operative behavior modifications (e.g., elevation, changes in activity, or improvements in compliance with compression). For example, Chang et al. used a non-validated survey tool and reported initial improvement after LVB in $95 \%$ of patients [28]. However, improvement was only sustained in $80 \%$ at one year after surgery.

In the eighteen papers that report individual patient data, we noted that the majority of patients $(50 \%-100 \%)$ improve following LVB or VLNT. In four studies, all patients reported improvement. The remaining studies have a small percentage of patients who either experienced no change or were 
worse. This is an important finding to consider. While most studies focus on the improvements after physiologic surgical treatment of lymphedema, negative results are also important and have a direct impact on patient counseling. However, due to the progressive nature of the disease, determining the etiology of worsening QOL post-operatively is difficult. While it is possible that surgery could damage functional lymphatics leading to increased lymphedema and decreased $\mathrm{QOL}$, it is also possible that these surgical interventions failed to improve lymphatic drainage and the disease, as expected, worsened over time.

Our study shows that there is little consensus in the literature on the use of PROMs to study outcomes following lymphatic surgery. Indeed, many studies reviewed in our paper (half of the papers that met inclusion criteria), failed to use validated instruments and relied on questionnaires developed in an ad hoc manner. Validated PROMs are developed using rigorous qualitative and quantitative psychometric methods to ensure that reliable, accurate, interpretable data is obtained and that the measurement tool is well targeted to the population being studied [58]. Therefore, to examine changes in QOL specific to lymphedema, the use of a validated PROM is critical to surgical outcomes research and advancement of this field. In this study, we noted that the proportion of published studies using a validated PROM has steadily increased over time. With the exception of one prior study, physiologic surgical treatment for lymphedema research began including QOL as an outcome measure in 2009. The earlier studies more often used non-validated tools or generic tools like the SF-36, even though the ULL27 was validated in 2002. The LYMQOL was validated in 2010 and has become the most widely applied tool since. While the use of validated tools is becoming more common, some recent studies continue to use non-validated measures. Considering the number of validated tools available and the ease of accessibility, the use of a validated tool in lymphedema research should be standard.

Among the 16 studies with validated PROMs, a variety of measures were used, including the LYMQOL $(n=12)$, ULL27 $(n=1)$, LLIS $(n=1)$, Lymph-ICF $(n=1)$, and SF-36 $(n=1)$. This heterogeneity makes comparison of outcomes across studies difficult. Consensus among lymphedema researchers regarding which QOL(s) to use is therefore important and necessary.

Which tool should be recommended? While the SF-36 is well known and widely used, a lymphedema-specific PROM which captures the particular psychologic, social and physical factors contributing to quality of life changes caused by lymphedema is likely more useful. When examining the efficacy of surgical procedures aimed at treating lymphedema, a lymphedema-specific evaluation tool ensures QOL changes are specific to lymphedema, compared to the use of a generic tool such as the SF-36 which would evaluate a general health status. The LYMQOL, ULL27, LLIS, and Lymph-ICF are all validated and comprehensive, lymphedema-specific questionnaires. In 2013, Pusic et al. evaluated lymphedema-specific PROMs and found the ULL27 had strong psychometric properties [59]. Since that time, however, the clinical characteristics of patients eligible for lymphedema surgery has shifted, with patients with less severe disease potentially benefitting. Given this, it is unclear whether the ULL27 continues to be well targeted across the entire spectrum of the patients. In terms of PROM contents, all evaluated physical and psychosocial issues that can affect patients with lymphedema. The LYMQOL also asks about worry, irritability, feeling of being tense, and depression that can plague those suffering from lymphedema. Similarly, the ULL27 asks about feeling sad, discouraged, distressed, or angry. The LLIS inquiries about feelings of depression, frustration or anger and the Lymph-ICF asks about feeling sad, frustrated and insecure about the future due to lymphedema but neither not touch on feelings of anxiety as directly. The LYMQOL, LLIS and Lymph-ICF are available for both upper and lower extremity evaluation, while the ULL27 is dedicated to upper extremity only.

An important limitation of our review is that it was outside the scope of our study to critically appraise the development and validation process of the lymphedema-specific PROMs identified in our search. Future research is needed that employs the COSMIN (COnsensus-based Standards for the selection of health Measurement Instruments) methodology, now used in an increasing number of reviews of PROMs, to examine the development process and psychometric properties of each PROM. The COSMIN methodology provides guidance and criteria for judging a range of psychometric 
properties, including content validity, structural validity, internal consistency, cross-cultural validity, reliability, measurement error, criterion validity, construct validity and responsiveness. Research that appraises PROMs using the COSMIN approach, could help to answer the question on which is the best PROM to use in future research [60].

This study has additional limitations. Summarization of outcomes specific to primary versus secondary lymphedema, upper extremity versus lower extremity is difficult as results regarding quality of life are often reported grouped together, including all patients in the study. Similarly, assessment of VLNT versus LVB is difficult, as some authors perform both treatments simultaneously or include a physiologic surgery with a reductive surgery. Additionally, this review is specific to physiologic procedures to treat lymphedema. Other survey tools may be used more predominantly in other fields, such a lymphedema therapy. Also, while we do see an improvement in quality of life in this study, no studies were blinded and therefore there may be a component of placebo effect. Further, more rigorous studies using a validated PROMs, preferably one common tool across all lymphedema research, with longer follow up, are needed to confirm the improvement in QOL in patients undergoing physiologic procedures for treatment of lymphedema.

\section{Conclusions}

Patients who suffer from lymphedema and undergo treatment with physiologic procedures such as LVB or VLNT have significant improvements in QOL. The use of lymphedema-specific PROMs has increased progressively over the past decade. This is important since QOL changes related to lymphedema may not correlate with limb volumes and because surgical treatments have the highest efficacy in patient with early stage (i.e., low volume) disease. Additional studies are needed using validated tools to confirm QOL improvements after LVB or VLNT and to guide patient selection, shared surgical decision making and future innovation.

Author Contributions: Conceptualization, M.C., B.M., J.D.; Methodology, M.C., J.G.; Formal Analysis, M.C., J.G., D.N., N.S.; Investigation, M.C., J.G., D.N., N.S.; Data Curation, M.C.; Writing Original Draft Preparation, M.C., J.D., A.K., A.P., B.M.; Writing Review \& Editing, M.C., J.D., A.K., A.P., B.M. All authors have read and agreed to the published version of the manuscript.

Conflicts of Interest: The authors declare no conflict of interest.

\section{References}

1. Lawenda, B.D.M.T.; Johnstone, P.A.S. Lymphedema: A primer on the identification and management of a chronic condition in oncologic treatment. Cancer J. Clin. 2009, 59, 8-24. [CrossRef] [PubMed]

2. Ribeiro Pereira, A.C.P.K.R.; Bergmann, A. Incidence and risk factors of lymphedema after breast cancer treatment: 10 years of follow-up. Breast 2017, 36, 67-73. [CrossRef] [PubMed]

3. Cormier, J.N.A.R.; Mungovan, K.S.; Xing, Y.; Ross, M.I.; Armer, J.M. Lymphedema beyond breast cancer. Cancer 2010, 116, 5138-5149. [CrossRef] [PubMed]

4. Todo, Y.Y.R.; Minobe, S.; Suzuki, Y.; Takeshi, U.; Nakatani, M.; Aoyagi, Y.; Ohba, Y.; Okamoto, K.; Kato, H. Risk factors for postoperative lower-extremity lymphedema in endometrial cancer survivors who had treatment including lymphadenectomy. Gynecol. Oncol. 2010, 119, 60-64. [CrossRef]

5. Zou, L.L.F.; Shen, P.P.; Hu, Y.; Liu, X.Q.; Xu, Y.Y.; Pen, Q.L.; Wang, B.; Zhu, Y.Q.; Tian, Y. The incidence and risk factors of related lymphedema for breast cancer survivors post-operation: A 2-year follow-up prospective cohort study. Breast Cancer 2018, 5, 309-314. [CrossRef]

6. Carlson, J.W.K.J.; Hutson, A.; Carter, J.; Armer, J.; Lockwood, S.; Nolte, S.; Stewart, B.R.; Wenzel, L.; Walker, J.; Fleury, A.; et al. GOG 244-The lymphedema and gynecologic cancer (LEG) study: Incidence and risk factors in newly diagnosed patients. Gynecol. Oncol. 2020, 156, 467-474. [CrossRef]

7. Zhang, Z.Z.X.; Chen, S.; Jiang, J.; Qi, R.; Zhang, X.; Xi, Y.; Li, M.; Zheng, H.; Hua, B. Taxane-based chemotherapy and risk of breast cancer-related lymphedema: Protocol for a systematic review and meta-analysis. Medicine 2019, 98, e16563. [CrossRef] 
8. Byun, H.K.C.J.; Im, S.H.; Kirova, Y.M.; Arsene-Henry, A.; Choi, S.H.; Cho, Y.U.; Park, H.S.; Kim, J.Y.; Suh, C.O.; Keum, K.C.; et al. Risk of Lymphedema Following Contemporary Treatment for Breast Cancer: An Analysis of 7617 Consecutive Patients From a Multidisciplinary Perspective. Ann. Surg. 2019. epub ahead of print. [CrossRef]

9. Michelotti, A.I.M.; Lopez, G.; Lorenzini, D.; Nesa, F.; De Sire, A.; Fusco, N. Tackling the diversity of breast cancer related lymphedema: Perspectives on diagnosis, risk assessment, and clinical management. Breast 2019, 44, 15-23. [CrossRef]

10. Huang, J.Y.N.; Wang, X.; Long, X. Incidence of lower limb lymphedema after vulvar cancer: A systematic review and meta-analysis. Medicine 2017, 96, e8722. [CrossRef]

11. Lindqvist, E.W.M.; Fredrikson, M.; Kjølhede, P. Lymphedema after treatment for endometrial cancer-A review of prevalence and risk factors. Eur. J. Obstet. Gynecol. Reprod. Biol. 2017, 211, 112-121. [CrossRef] [PubMed]

12. Gupta, A.M.J. Lymphedema. JAMA Oncol. 2018, 4, 755. [CrossRef] [PubMed]

13. Warren, A.G.B.H.; Borud, L.J.; Slavin, S.A. Lymphedema: A comprehensive review. Ann. Plast. Surg. 2007, 59, 464-472. [CrossRef] [PubMed]

14. Hayes, S.C.J.K.; Stout, N.L.; Prosnitz, R.; Armer, J.M.; Gabram, S.; Schmitz, K.H. Upper-body morbidity after breast cancer: Incidence and evidence for evaluation, prevention, and management within a prospective surveillance model of care. Cancer 2012, 118, 2237-2249. [CrossRef] [PubMed]

15. Hormes, J.M.B.C.; Lytle, L.A.; Gross, C.R.; Ahmed, R.L.; Troxel, A.B.; Schmitz, K.H. Impact of lymphedema and arm symptoms on quality of life in breast cancer survivors. Lymphology 2010, 43, 1-13. [PubMed]

16. Keeley, V.C.S.; Locke, J.; Veigas, D.; Riches, K.; Hilliam, R. A quality of life measure for limb lymphoedema (LYMQOL). J. Lymphoedema 2010, 5, 26-37.

17. Launois, R.M.A.; Pocquet, K.; Alliot, F. A specific quality of life scale in upper limb lymphoedema: The ULL-27 questionnaire. Lymphology 2002, 35, 181-187. [CrossRef]

18. Devoogdt, N.V.K.M.; Geraerts, I.; Coremans, T.; Christiaens, M.R. Lymphoedema Functioning, Disability and Health questionnaire (Lymph-ICF): Reliability and validity. Phys. Ther. 2011, 91, 944-957. [CrossRef]

19. Weiss, J.D.T. Validation of the Lymphedema Life Impact Scale (LLIS): A Condition-Specific Measurement Tool for Persons with Lymphedema. Lymphology 2015, 48, 128-138.

20. Treanor, C.D.M. A methodological review of the Short Form Health Survey 36 (SF-36) and its derivatives among breast cancer survivors. Qual. Life Res. 2015, 24, 339-362. [CrossRef]

21. Carl, H.M.W.G.; Bello, R.; Clarke-Pearson, E.; Hassanein, A.H.; Cho, B.; Pedreira, R.; Sacks, J.M. Systematic Review of the Surgical Treatment of Extremity Lymphedema. J. Reconstr. Microsurg. 2017, 33, 412-425. [CrossRef] [PubMed]

22. Cochrane Handbook for Systematic Reviews of Interventions, Version 5.1.0 ed.; The Cochrane Collaboration: London, UK, 2011.

23. Bramer, W.M.G.D.; de Jonge, G.B.; Holland, L.; Bekhuis, T. De-duplication of database search results for systematic reviews in EndNote. J. Med. Libr. Assoc. 2016, 4, 240-243. [CrossRef] [PubMed]

24. O’Brien, B.M.; Mellow, C.G.; Khazanchi, R.K.; Dvir, E.; Kumar, V.; Pederson, W.C. Long-term results after microlymphaticovenous anastomoses for the treatment of obstructive lymphedema. Plast. Reconstr. Surg. 1990, 85, 562-572. [CrossRef] [PubMed]

25. Demirtas, Y.O.N.; Yapici, O.; Topalan, M. Supermicrosurgical lymphaticovenular anastomosis and lymphaticovenous implantation for treatment of unilateral lower extremity lymphedema. Microsurgery 2009, 29, 609-618. [CrossRef] [PubMed]

26. Auba, C.; Marre, D.; Rodriguez-Losada, G.; Hontanilla, B. Lymphaticovenular anastomoses for lymphedema treatment: 18 months postoperative outcomes. Microsurgery 2012, 32, 261-268. [CrossRef]

27. Ayestaray, B.B.F.; Andreoletti, J.B. Patent blue-enhanced lymphaticovenular anastomosis. J. Plast. Reconstr. Aesthet. Surg. 2013, 66, 382-389. [CrossRef]

28. Chang, D.W. Lymphaticovenular bypass for lymphedema management in breast cancer patients: A prospective study. Plast. Reconstr. Surg. Glob. Open. 2010, 126, 752-758. [CrossRef]

29. Chang, D.W.; Suami, H.; Skoracki, R. A prospective analysis of 100 consecutive lymphovenous bypass cases for treatment of extremity lymphedema. Plast. Reconstr. Surg. Glob. Open. 2013, 132, 1305-1314. [CrossRef] 
30. Poumellec, M.A.; Foissac, R.; Cegarra-Escolano, M.; Barranger, E.; Ihrai, T. Surgical treatment of secondary lymphedema of the upper limb by stepped microsurgical lymphaticovenous anastomoses. Breast Cancer Res. Treat. 2017, 162, 219-224. [CrossRef]

31. Chung, J.H.; Baek, S.O.; Park, H.J.; Lee, B.I.; Park, S.H.; Yoon, E.S. Efficacy and patient satisfaction regarding lymphovenous bypass with sleeve-in anastomosis for extremity lymphedema. Arch. Plast. Surg. 2019, 46, 46-56. [CrossRef]

32. Mihara, M.; Hara, H.; Kikuchi, K.; Yamamoto, T.; Iida, T.; Narushima, M.; Araki, J.; Murai, N.; Mitsui, K.; Gennaro, P.; et al. Scarless lymphatic venous anastomosis for latent and early-stage lymphoedema using indocyanine green lymphography and non-invasive instruments for visualising subcutaneous vein. J. Plast. Reconstr. Aesthet. Surg. 2012, 65, 1551-1558. [CrossRef] [PubMed]

33. Mihara, M.; Hara, H.; Tange, S.; Zhou, H.P.; Kawahara, M.; Shimizu, Y.; Murai, N. Multisite Lymphaticovenular Bypass Using Supermicrosurgery Technique for Lymphedema Management in Lower Lymphedema Cases. Plast. Reconstr. Surg. 2016, 138, 262-272. [CrossRef] [PubMed]

34. Chen, W.F.; Zhao, H.; Yamamoto, T.; Hara, H.; Ding, J. Indocyanine Green Lymphographic Evidence of Surgical Efficacy Following Microsurgical and Supermicrosurgical Lymphedema Reconstructions. J. Reconstr. Microsurg. 2016, 32, 688-698. [PubMed]

35. Masia, J.; Pons, G.; Rodriguez-Bauza, E. Barcelona Lymphedema Algorithm for Surgical Treatment in Breast Cancer-Related Lymphedema. J. Reconstr. Microsurg. 2016, 32, 329-335.

36. Winters, H.; Tielemans, H.J.P.; Hameeteman, M.; Paulus, V.A.A.; Beurskens, C.H.; Slater, N.J.; Ulrich, D.J.O. The efficacy of lymphaticovenular anastomosis in breast cancer-related lymphedema. Breast Cancer Res. Treat. 2017, 165, 321-327. [CrossRef]

37. Winters, H.; Tielemans, H.J.P.; Verhulst, A.C.; Paulus, V.A.A.; Slater, N.J.; Ulrich, D.J.O. The Long-term Patency of Lymphaticovenular Anastomosis in Breast Cancer-Related Lymphedema. Ann. Plast. Surg. 2019, 82, 196-200. [CrossRef]

38. Gentileschi, S.; Servillo, M.; Albanese, R.; De Bonis, F.; Tartaglione, G.; Salgarello, M. Lymphatic mapping of the upper limb with lymphedema before lymphatic supermicrosurgery by mirroring of the healthy limb. Microsurgery 2017, 37, 881-889. [CrossRef]

39. Salgarello, M.; Mangialardi, M.L.; Pino, V.; Gentileschi, S.; Visconti, G. A Prospective Evaluation of Health-Related Quality of Life following Lymphaticovenular Anastomosis for Upper and Lower Extremities Lymphedema. J. Reconstr. Microsurg. 2018, 34, 701-707. [CrossRef]

40. Cornelissen, A.J.M.; Kool, M.; Lopez Penha, T.R.; Keuter, X.H.A.; Piatkowski, A.A.; Heuts, E.; van der Hulst, R.; Qiu, S.S. Lymphatico-venous anastomosis as treatment for breast cancer-related lymphedema: A prospective study on quality of life. Breast Cancer Res. Treat. 2017, 163, 281-286. [CrossRef]

41. Damstra, R.J.; Voesten, H.G.; van Schelven, W.D.; van der Lei, B. Lymphatic venous anastomosis (LVA) for treatment of secondary arm lymphedema. A prospective study of 11 LVA procedures in 10 patients with breast cancer related lymphedema and a critical review of the literature. Breast Cancer Res. Treat. 2009, 113, 199-206. [CrossRef]

42. Gharb, B.B.; Rampazzo, A.; Spanio di Spilimbergo, S.; Xu, E.S.; Chung, K.P.; Chen, H.C. Vascularized lymph node transfer based on the hilar perforators improves the outcome in upper limb lymphedema. Ann. Plast. Surg. 2011, 67, 589-593. [CrossRef] [PubMed]

43. Nguyen, A.T.; Suami, H.; Hanasono, M.M.; Womack, V.A.; Wong, F.C.; Chang, E.I. Long-term outcomes of the minimally invasive free vascularized omental lymphatic flap for the treatment of lymphedema. J. Surg. Oncol. 2017, 115, 84-89. [CrossRef] [PubMed]

44. Coriddi, M.; Wee, C.; Meyerson, J.; Eiferman, D.; Skoracki, R. Vascularized Jejunal Mesenteric Lymph Node Transfer: A Novel Surgical Treatment for Extremity Lymphedema. J. Am. Coll. Surg. 2017, 225, 650-657. [CrossRef] [PubMed]

45. Dionyssiou, D.; Demiri, E.; Tsimponis, A.; Sarafis, A.; Mpalaris, V.; Tatsidou, G.; Arsos, G. A randomized control study of treating secondary stage II breast cancer-related lymphoedema with free lymph node transfer. Breast Cancer Res. Treat. 2016, 156, 73-79. [CrossRef]

46. Ciudad, P.; Maruccia, M.; Socas, J.; Lee, M.H.; Chung, K.P.; Constantinescu, T.; Kiranantawat, K.; Nicoli, F.; Sapountzis, S.; Yeo, M.S.; et al. The laparoscopic right gastroepiploic lymph node flap transfer for upper and lower limb lymphedema: Technique and outcomes. Microsurgery 2017, 37, 197-205. [CrossRef] 
47. Patel, K.M.; Lin, C.Y.; Cheng, M.H. A Prospective Evaluation of Lymphedema-Specific Quality-of-Life Outcomes Following Vascularized Lymph Node Transfer. Ann. Surg. Oncol. 2015, 22, 2424-2430. [CrossRef]

48. Asuncion, M.O.; Chu, S.Y.; Huang, Y.L.; Lin, C.Y.; Cheng, M.H. Accurate Prediction of Submental Lymph Nodes Using Magnetic Resonance Imaging for Lymphedema Surgery. Plast. Reconstr. Surg. Glob. Open. 2018, 6, e1691. [CrossRef]

49. Ciudad, P.; Manrique, O.J.; Adabi, K.; Huang, T.C.; Agko, M.; Trignano, E.; Chang, W.L.; Chen, T.W.; Salgado, C.J.; Chen, H.C. Combined double vascularized lymph node transfers and modified radical reduction with preservation of perforators for advanced stages of lymphedema. J. Surg. Oncol. 2019, 119, 439-448. [CrossRef]

50. Visconti, G.; Tartaglione, G.; Bartoletti, R.; Salgarello, M. Ompartimental harvesting of dual lymph node flap from the right supraclavicular area for the treatment of lower extremity lymphedema: A case series. J. Plast. Reconstr. Aesthet. Surg. 2019, 72, 211-215. [CrossRef]

51. Maruccia, M.; Elia, R.; Ciudad, P.; Nacchiero, E.; Nicoli, F.; Vestita, M.; Chen, H.C.; Giudice, G. Postmastectomy upper limb lymphedema: Combined vascularized lymph node transfer and scar release with fat graft expedites surgical and patients' related outcomes. A retrospective comparative study. J. Plast. Reconstr. Aesthet. Surg. 2019, 72, 892-901. [CrossRef]

52. Gratzon, A.; Schultz, J.; Secrest, K.; Lee, K.; Feiner, J.; Klein, R.D. Clinical and Psychosocial Outcomes of Vascularized Lymph Node Transfer for the Treatment of Upper Extremity Lymphedema After Breast Cancer Therapy. Ann. Surg. Oncol. 2017, 24, 1475-1481. [CrossRef]

53. Cheng, M.H.; Loh, C.Y.Y.; Lin, C.Y. Outcomes of Vascularized Lymph Node Transfer and Lymphovenous Anastomosis for Treatment of Primary Lymphedema. Plast. Reconstr. Surg. Glob. Open. 2018, 6, e2056. [CrossRef] [PubMed]

54. De Brucker, B.; Zeltzer, A.; Seidenstuecker, K.; Hendrickx, B.; Adriaenssens, N.; Hamdi, M. Breast Cancer-Related Lymphedema: Quality of Life after Lymph Node Transfer. Plast. Reconstr. Surg. Glob. Open. 2016, 137, 1673-1680. [CrossRef] [PubMed]

55. Inbal, A.; Teven, C.M.; Chang, D.W. Latissimus dorsi flap with vascularized lymph node transfer for lymphedema treatment: Technique, outcomes, indications and review of literature. J. Surg. Oncol. 2017, 115, 72-77. [CrossRef] [PubMed]

56. Wiser, I.M.B.; Coriddi, M.; Kenworthy, E.; Cavalli, M.; Encarnacion, E.; Dayan, J. Preoperative Assessment of Upper Extremity Secondary Lymphedema. Cancers 2020, 12, 135. [CrossRef] [PubMed]

57. Armer, J.M.B.K.; McCall, L.; Armer, N.C.; Sun, Y.; Udmuangpia, T.; Hunt, K.K.; Mittendorf, E.A.; Byrd, D.R.; Julian, T.B.; Boughey, J.C. Lymphedema symptoms and limb measurement changes in breast cancer survivors treated with neoadjuvant chemotherapy and axillary dissection: Results of American College of Surgeons Oncology Group (ACOSOG) Z1071 (Alliance) substudy. Support Care Cancer 2019, 27, 495-503. [CrossRef]

58. Tsang, S.R.C.; Terkawi, A.S. Guidelines for developing, translating, and validating a questionnaire in perioperative and pain medicine. Saudi. J. Anaesth. 2017, 11, S80-S89. [CrossRef]

59. Pusic, A.L.C.Y.; Albornoz, C.; Klassen, A.; Cano, S.; Sulimanoff, I.; Hernandez, M.; Massey, M.; Cordeiro, P.; Morrow, M.; Mehrara, B. Quality of life among breast cancer patients with lymphedema: A systematic review of patient-reported outcome instruments and outcomes. J. Cancer Surviv. 2013, 7, 83-92. [CrossRef]

60. Mokkink, L.B.; Prinsen, C.; Patrick, D.L.; Alonso, J.; Bouter, L.M.; de Vet, H.C.; Terwee, G.B. COSMIN methodology for systematic reviews of Patient-Reported Outcome Measures (PROMs). User Man. 2018, 78, 1.

(C) 2020 by the authors. Licensee MDPI, Basel, Switzerland. This article is an open access article distributed under the terms and conditions of the Creative Commons Attribution (CC BY) license (http://creativecommons.org/licenses/by/4.0/). 